\title{
How to Assess Regional and Whole Gut Transit Time With Wireless Motility Capsule
}

\author{
Yeong Yeh Lee, ${ }^{1,2 *}$ Askin Erdogan ${ }^{2}$ and Satish S C Rao ${ }^{2}$ \\ ${ }^{1}$ School of Medical Sciences, Universiti Sains Malaysia, Kubang Kerian, Kota Bahru, Kelantan, Malaysia; and ${ }^{2}$ Department of Medicine, Section \\ of Gastroenterology and Hepatology, Georgia Regents University, Augusta, Georgia, USA
}

\begin{abstract}
Assessment of transit through the gastrointestinal tract provides useful information regarding gut physiology and pathophysiology. Although several methods are available, each has distinct advantages and limitations. Recently, an ingestible wireless motility capsule (WMC), similar to capsule video endoscopy, has become available that offers a less-invasive, standardized, radiation-free and office-based test. The capsule has 3 sensors for measurement of pH, pressure and temperature, and collectively the information provided by these sensors is used to measure gastric emptying time, small bowel transit time, colonic transit time and whole gut transit time. Current approved indications for the test include the evaluation of gastric emptying in gastroparesis, colonic transit in constipation and evaluation of generalised dysmotility. Rare capsule retention and malfunction are known limitations and some patients may experience difficulty with swallowing the capsule. The use of WMC has been validated for the assessment of gastrointestinal transit. The normal range for transit time includes the following: gastric emptying (2-5 hours), small bowel transit (2-6 hours), colonic transit (10-59 hours) and whole gut transit (10-73 hours). Besides avoiding the use of multiple endoscopic, radiologic and functional gastrointestinal tests, WMC can provide new diagnoses, leads to a change in management decision and help to direct further focused work-ups in patients with suspected disordered motility. In conclusion, WMC represents a significant advance in the assessment of segmental and whole gut transit and motility, and could prove to be an indispensable diagnostic tool for gastrointestinal physicians worldwide.
\end{abstract}

(J Neurogastroenterol Motil 2014;20:265-270)

\section{Key Words}

Constipation; Gastric emptying; Gastrointestinal transit; Gastrointestinal motility

\section{Introduction}

Disturbances in motility and transit are common in functional gastrointestinal (GI) disorders such as irritable bowel syndrome, functional dyspepsia, gastroparesis, bloating or chronic idiopathic constipation. Because of the heterogeneous and overlapping nature of symptoms, it is often difficult to pinpoint which GI region is affected, and therefore a comprehensive evaluation of GI transit study can be useful. Knowledge of abnormal transit in these disorders will assist in planning appropriate management strategies.

Received: February 13, 2014 Revised: February 17, 2014 Accepted: February 17, 2014

(c) This is an Open Access article distributed under the terms of the Creative Commons Attribution Non-Commercial License (http://creativecommons. org/licenses/by-nc/3.0) which permits unrestricted non-commercial use, distribution, and reproduction in any medium, provided the original work is properly cited.

*Correspondence: Yeong Yeh Lee, MD, PhD, FACP, FRCP

School of Medical Sciences, Universiti Sains Malaysia, 16150 Kubang Kerian, Kelantan, Malaysia

Tel: +6097676590, Fax: +6097673949, E-mail: justnleeyy@gmail.com

Financial support: None.

Conflicts of interest: Satish S C Rao serves as an advisory board member and has received research funding from SmartPill, Given Imaging Inc. Other authors did not report any conflicts of interest.

ORCID: Yeong Yeh Lee, http://orcid.org/0000-0002-6486-7717. 

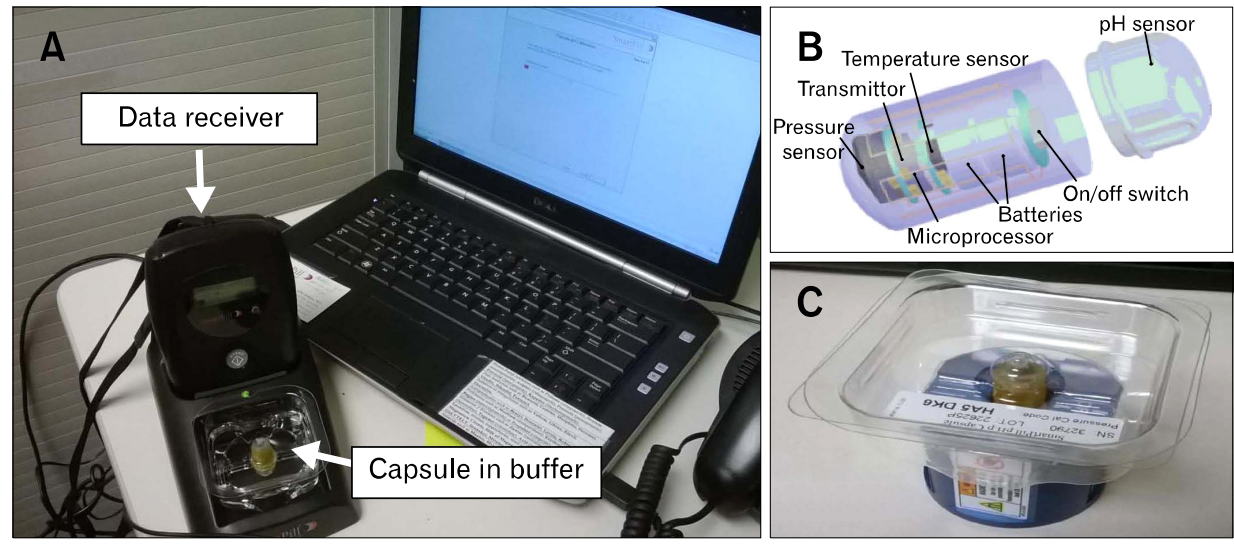

Figure 1. Equipments used for the SmartPill test. (A) The data receiver and laptop with the MotiliGI software is shown. The SmartPill capsule in the buffer is also shown. (B) The inside of a SmartPill capsule. (C) Activation of SmartPill capsule with a magnetic fixture.
Whole gut and regional transit time can be measured with different techniques including scintigraphy, breath tests and radio-opaque markers. ${ }^{1}$ These techniques are limited by their availability, exposure to radiation and lack of standardization between centers. Antroduodenal or small bowel manometry and colonic manometry allow reliable physiological measurement of the GI tract but these tests are invasive and are only available in relatively few centers. An ingestible wireless motility capsule (WMC), which is similar to the capsule video endoscopy, is now available as a less-invasive alternative to the measurement of gut transit. ${ }^{2}$ The capsule does not require any radiation and the methodology has been standardized both for study performance and study interpretation when compared to other techniques.

\section{Test Equipment}

WMC (SmartPill; Given-Imaging Corp., Yoqneam, Israel) is a single use, ingestible but indigestible capsule measuring 26.8 $\mathrm{mm}$ in length and $11.7 \mathrm{~mm}$ in diameter. It houses sensors for $\mathrm{pH}$ (range 0.5-9.0, accuracy $\pm 0.5 \mathrm{pH}$ units), pressure (range 0-350 $\mathrm{mmHg}$, accuracy $\pm 5 \mathrm{mmHg}$ ) and also temperature (range $25-49^{\circ} \mathrm{C}$, accuracy $\pm 2{ }^{\circ} \mathrm{C}$ ) (Fig. 1 ). The capsule samples data every 20 seconds for the first 24 hours and every 40 seconds thereafter.

Prior to ingestion, the capsule requires activation using a magnetic fixture followed by $\mathrm{pH}$ calibration using the provided buffer. After activation and ingestion, the activated capsule transmits signals from the GI tract that are captured by the data receiver that is worn for the next 5 days. The data recorder is placed on a data logger that is designed to interface with a laptop for transmission. The software, MotiliGI (Given Imaging Corp.) will assist in interpretation of test results by a physician and in en- tering events during the test.

\section{Test Procedure}

The patients are instructed to fast overnight and attend a motility lab. Certain medications (including proton-pump inhibitors, $\mathrm{H}_{2}$ receptor antagonist, prokinetics, antiemetic agents, anticholinergic agents, laxatives, narcotic analgesics and nonsteroidal anti-inflammatory drugs) should be discontinued 3 to 7 days prior to the test. After a standardized meal, a nutrient bar (Smartbar; Given Imaging Corp.) with calorie similar to an egg sandwich and $50 \mathrm{~mL} \mathrm{H}_{2} \mathrm{O}$, the WMC is ingested, and the subject is not permitted to eat or drink for the next 6 hours in order to assess gastric emptying time (GET). Patient is usually monitored in the lab for 1 hour after WMC ingestion. Subsequently, the patient is allowed to eat and drink as usual and wear the data receiver as shown in Figure 1 for the next 3-5 days. The subject is instructed to push the button on the receiver when certain events occur and also to keep a diary of these events (including meals, sleep, bowel movements and symptoms) so that they can be entered manually and to correlate events with manometric changes. Although study subjects are mobile during the study period, strenuous physical activities should be avoided since this may affect pressure reading. At the end of 5 days, the recorder is returned and data are downloaded via a docking station for subsequent analysis. Patient may or may not notice that they have passed the capsule but a loss of signal denoted by a "X" mark on the receiver screen, usually following a bowel movement, is a clue that the capsule has exited from the body. 
Table. Analysis and Interpretations of Gut Transit Time With Wireless Motility Capsule

\begin{tabular}{|c|c|c|c|c|c|}
\hline Landmarks & Identification & $\begin{array}{l}\text { Transit } \\
\text { time (hr) }\end{array}$ & Indications & Trouble-shooting & Reference \\
\hline Body entry & Temperature rises to body temperature & - & - & $\begin{array}{l}\text { Large capsule difficult to swallow, in } \\
\text { which PillCam delivery device may be } \\
\text { useful. }\end{array}$ & {$[3]$} \\
\hline Gastric emptying & $\begin{array}{l}\text { The } \mathrm{pH} \text { drops to stomach baseline } \\
\text { marks entry. Abrupt rise in the } \mathrm{pH} \\
(>3 \mathrm{pH} \text { units) from stomach base- } \\
\text { line marks exit. }\end{array}$ & $2-5$ & Gastroparesis & $\begin{array}{l}\text { Use of proton pump inhibitors may reduce } \\
\mathrm{pH} \text { change. Look at doubling of stomach } \\
\text { and small bowel contractions during } \\
\text { emptying if } \mathrm{pH} \text { is non-confirmatory. } \\
\text { Beware of fed response. }\end{array}$ & $\begin{array}{l}{[4],[6]} \\
{[7],[10]}\end{array}$ \\
\hline Small bowel transit & $\begin{array}{l}\text { The } \mathrm{pH} \text { rise marks entry. An abrupt } \\
\mathrm{pH} \text { drop of at least } 1 \mathrm{pH} \text { unit observed } \\
\text { at least } 30 \text { min after gastric emptying } \\
\text { marks exit from ileocecal junction. }\end{array}$ & $2-6$ & $\begin{array}{l}\text { Unclear but } \\
\text { include } \\
\text { upper and } \\
\text { lower GI } \\
\text { dysmotility }\end{array}$ & $\begin{array}{l}\text { The } \mathrm{pH} \text { drop not seen in } 5-15 \% \text { of cases } \\
\text { due to ileocecal incompetence or altered } \\
\text { microbiota. In such cases, calculate small } \\
\text { and large bowel transit time together. }\end{array}$ & {$[1],[8]$} \\
\hline Large bowel transit & $\begin{array}{l}\text { The } \mathrm{pH} \text { drop marks entry into cecum. } \\
\text { Exit of body is mark by drop of } \\
\text { temperature to room temperature or } \\
\text { loss of signal. Capsule may be identi- } \\
\text { fied during defecation. }\end{array}$ & $10-59$ & $\begin{array}{l}\text { Slow transit } \\
\text { constipation }\end{array}$ & $\begin{array}{l}\text { If capsule not passed, there is a possibility } \\
\text { of retention. Needs radiological identifi- } \\
\text { cation in this case. pH data may be } \\
\text { useful to locate the non-exited capsule. }\end{array}$ & $\begin{array}{l}{[1],[2]} \\
{[5],[12]}\end{array}$ \\
\hline
\end{tabular}

GI, gastrointestinal.

\section{Trouble-shooting During the Test and Complications (see Table)}

Some subjects may experience difficulty with swallowing the WMC. The test is contraindicated in patients with history of dysphagia, any oropharyngeal or esophageal stricture, or functional abnormality. Occasionally, several attempts may be needed. In those who fail to swallow the WMC, attempting for more than half an hour, placement can be aided by grasping the capsule with the PillCam (Given Imaging Corp.) delivery device (Fig. 2) and then inserted directly into the stomach. Ideally this should be done under fluoroscopic guidance to ensure capsule delivery into the stomach. A recent report described successful placement of WMC in all three subjects. ${ }^{3}$ Equipment malfunction is less common nowadays from a recent upgrade of the system. There is a risk for capsule retention, for as long as 26 days in reported surveillance but the retention rate is rare at $0.33 \%$ based on a post-market analysis of 6,000 capsules. ${ }^{1}$ Prolonged retention for more than 2 weeks is confirmed by radiological identification and in some cases endoscopic retrieval is required. Most retained capsules would eventually exit from the body without the need for any invasive interventions although prokinetics or laxatives are frequently tried. The $\mathrm{pH}$ data may also assist in locating the non-exited capsule. Nevertheless, the test is contraindicated in

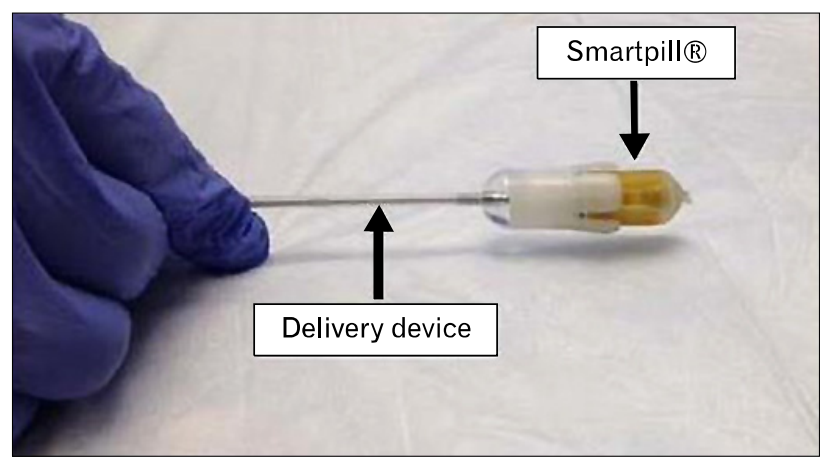

Figure 2. In cases where patients have difficulty in swallowing, direct delivery of the capsule into the stomach can be aided with a delivery device used for the PillCam.

patients with a known history of pseudo-obstruction or true obstruction, stricture, adhesion, ileus and gastric bezoar.

\section{Indications}

SmartPill is approved by the US Federal and Drug Administration for the evaluation of suspected delayed gastric emptying (gastroparesis) and in constipation to differentiate slow from normal colonic transit. The 2011 position paper of the American and European Neurogastroenterology and Motility Societies (ANMS 
and ESNM) also recommends WMC (SmartPill) for the evaluation of regional (stomach, small bowel and colon) and generalized GI (whole gut) motility disorders. ${ }^{1}$ Evidence suggests that many patients often have dysmotility that affects multiple regions rather than single region in the GI tract. ${ }^{4,5}$ In such cases, the WMC can eliminate the use of multiple tests that may include gastric emptying scintigraphy (GES), small bowel barium study and colonic radio-opaque markers (ROMs) or multiple repeat endoscopies or other radiological tests.

\section{Analysis and Interpretations}

\section{Normal Landmarks}

The gut is characterized by physiological and anatomical landmarks that are utilized to facilitate localization of the regional transit time. The $\mathrm{pH}$, temperature and pressure sensors on the WMC are utilized to help this. Upon ingestion of WMC, the room temperature will immediately rise to the body temperature, and this marks the entry time into the body. The initial $\mathrm{pH}$ can be high because of the meal given prior to capsule ingestion, but gradually this decreases and often an acidic $\mathrm{pH}$ profile of $1-2$ is registered in the stomach. GET is calculated from the time of ingestion up to the time when the profile shows an abrupt and sustained rise in the $\mathrm{pH}$ (usually $>3 \mathrm{pH}$ units) from the gastric baseline. The abrupt $\mathrm{pH}$ rise marks the passage of capsule from the antrum into the duodenum. ${ }^{6}$ The use of proton pump inhibitors may affect the magnitude of $\mathrm{pH}$ change, and therefore it should be avoided. One study showed that despite the use of proton pump inhibitors there was an abrupt and persistent $\mathrm{pH}$ change of $>0.5$ unit coinciding with capsule entry into the duodenum. ${ }^{7}$ If there is still a doubt, one can look at the changes in pressure activity. Gastric contractions present with usually less frequent and large whereas small bowel contractions are smaller amplitude. The presence of gastric or duodenal contractions should be documented. Next, the ileocecal junction is identified by an abrupt $\mathrm{pH}$ drop of at least $1 \mathrm{pH}$ unit that is sustained for 10 minutes and occurs at least 30 minutes after gastric emptying. In an elegant study using radioisotopes, the $\mathrm{pH}$ change was validated with cecal arrival time. ${ }^{8}$ This $\mathrm{pH}$ drop in the ileocecal region is a result of fermentation in cecum and short-chain fatty acids production which is maximal in this region. ${ }^{9}$ It is possible that in $15 \%$ of subjects, this $\mathrm{pH}$ drop is not observed and this may be related to the ileocecal valve incompetence. ${ }^{8}$ Body exit time is denoted by a temperature drop to room temperature and/or loss of signal with bowel movement.

\section{Abnormal Transit Time}

The cut-off for GET of 300 minutes provides a sensitivity of 0.65 and specificity of 0.87 for a diagnosis of gastroparesis. ${ }^{10}$ The best correlation was with the GES at 4 hours with a correlation coefficient of 0.73 . The capsule detects more delay in GET than GES (65\% vs. $44 \%$ ) presumably because it also measures the fasting state. ${ }^{10}$ On the other hand, the cut-off for rapid GET with the capsule is unclear since the 2-hour proposed cut-off is not validated against scintigraphy and there is only one study which has shown that WMC was diagnostically useful but the sample size was small. ${ }^{5}$ A very rapid GET may point to dumping syndrome.

Small bowel transit time (SBTT) is the time taken from entry of capsule in the duodenum until it has passed into the ileocecal region. The median SBTT in healthy volunteers is reported to be 4.6 hours (range $4.0-5.9$ hours, 25 th and 75 th percentiles), ${ }^{6}$ with rapid transit defined as less than 2.5 hours and delayed transit as more than 6 hours. There was a significant correlation in SBTT measured with the capsule and whole gut scintigraphy in normal volunteers $(r=0.69) .{ }^{11}$ Patients presenting with symptoms of upper and lower GI motility disorders have significantly slower SBTT compared to controls (447 vs. 301 minutes) but the exact clinical significance remains unclear. ${ }^{5}$ As previously mentioned, determination of SBTT may not be possible in some studies with poor $\mathrm{pH}$ landmarks.

Colonic transit time (CTT) is defined as the time between cecal entry of capsule and its exit from the body. Where time of cecal entry is not possible due to poor $\mathrm{pH}$ landmark (approximately $5 \%$ of cases), small and large bowel transit time is calculated. ${ }^{1}$ Measurement of CTT is indicated in patients with chronic constipation to distinguish slow from normal transit constipation. In studies using ROMs, the mean CTT was 30-40 hours (maximum 70 hours), with women having longer maximal CTT than men. ${ }^{12,13}$ Based on these studies, a delayed CTT with the capsule was defined as greater than 59 hours and a rapid transit as less than 5 hours. There was a good agreement in day 2 and day 5 CTT between the capsule and ROMs in healthy and constipated subjects. $^{5}$

Whole gut transit time (WGTT) is the combined transit time of GET, SBTT and CTT and is defined as delayed when greater than 73 hours and rapid transit as less than 10 hours. There was a good correlation between scintigraphic WGTT and the WMC. ${ }^{11}$ Constipated patients have been shown in a prospective study to have slower WGT besides slower GET and 


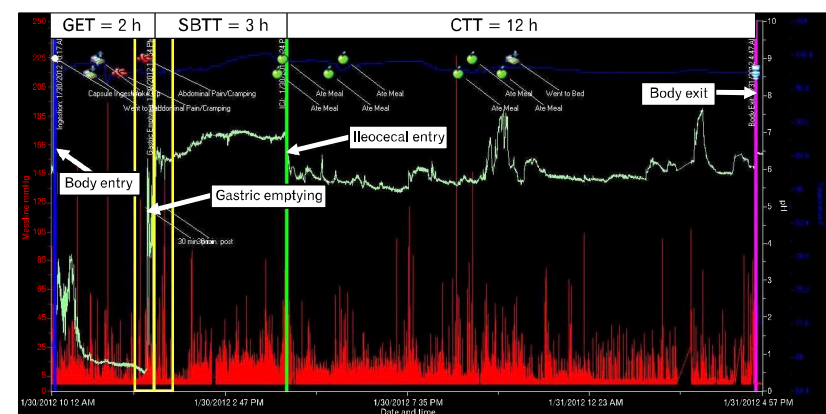

Figure 3. The gut transit profile in a patient with gastric emptying time (GET) of 2 hours, small bowel transit time (SBTT) of 3 hours and colonic transit time (CTT) of 12 hours. The tracings for temperature (blue), $\mathrm{pH}$ (green) and pressure (red) are shown, along with markers for body entry, gastric emptying, ileocecal entry and body exit.

\section{$\mathrm{CTT}^{2}$}

\section{Software-assisted Analysis}

The SmartPill's MotiliGI software allows the physician to analyse, report and export the findings with ease. There is an analysis wizard that guides the user in a step-by-step fashion through the data analysis. It assists in automatic calculation of GET, SBTT, CTT, combined SBTT/CTT and WGT in both graphical (Fig. 3) and statistical formats with a summary report at the end. Even though the software may help to point out the anatomical landmarks, these need to be verified and changed accordingly by the reporting physician. Also, any pressure events that may correlate with symptoms should be documented.

\section{How Clinically Useful Is Wireless Motility Capsule in Transit Measurement?}

In a group of 83 patients with suspected GI dysmotility, abnormal regional transit was found in $68 \%$ with $35.1 \%$ showing more generalized dysmotility in 2 or more regions. ${ }^{4}$ With WMC, it eliminates the use of multiple tests to diagnose the more generalized form of dysmotility. In addition, WMC leads to new diagnoses and allows significant change in management decisions in more than half of cases ${ }^{4,5}$ including the need for colectomy. It also guides further work-up for example anorectal manometry in dyssynergic defecation or other imaging studies.

\section{Other Uses of Wireless Motility Capsule -}

Besides functional GI diseases, recent evidence suggests that
WMC is useful in the evaluation of transit and gastric $\mathrm{pH}$ in critically-ill patients, ${ }^{14}$ cystic fibrosis, ${ }^{15}$ geriatric ${ }^{16}$ and also in the paediatric population. ${ }^{17}$ WMC also provides regional and the whole gut pressure measurements. The limitation lies in its one pressure sensor that also migrates within the gut lumen. As such, WMC will not be able to characterize propagation and certain contractile patterns in the small and large bowel including migrating motor complex and propagating contractions. Despite this limitation, there have been a number of studies that suggest pressure measurement with WMC may have a complementary role to measurement of transit including predicting severity of gastroparesis ${ }^{6}$ and providing mechanistic insight to slow-transit constipation. ${ }^{18,19}$ Other uses of WMC have included assessment of new drug effects on GI transit and their mechanisms of action. $^{20}$

\section{Conclusions}

WMC is truly an innovative non-invasive technology for the assessment of gut dysmotility. This technique eliminates the need for multiple tests, leads to new diagnoses and guides further work-ups and management decisions. Despite limitations including costs and lack of availability, this technology is continuing to evolve with new clinical indications and is expanding its horizons worldwide including Asia.

\section{References}

1. Rao SS, Camilleri M, Hasler WL, et al. Evaluation of gastrointestinal transit in clinical practice: position paper of the American and European Neurogastroenterology and Motility Societies. Neurogastroenterol Motil 2011;23:8-23.

2. Rao SS, Kuo B, McCallum RW, et al. Investigation of colonic and whole-gut transit with wireless motility capsule and radiopaque markers in constipation. Clin Gastroenterol Hepatol 2009;7:537544.

3. Erdogan A, Rao SS, Mack A. Peroral gastric placement of wireless motility capsule (WMC; Smartpill ${ }^{\mathbb{R}}$ ) under fluoroscopy: a novel method for patients with inability to swallow. Am J Gastroenterol 2013;108(suppl 1):S52.

4. Kuo B, Maneerattanaporn M, Lee AA, et al. Generalized transit delay on wireless motility capsule testing in patients with clinical suspicion of gastroparesis, small intestinal dysmotility, or slow transit constipation. Dig Dis Sci 2011;56:2928-2938.

5. Rao SS, Mysore K, Attaluri A, Valestin J. Diagnostic utility of wireless motility capsule in gastrointestinal dysmotility. J Clin Gastroenterol 2011;45:684-690.

6. Sarosiek I, Selover KH, Katz LA, et al. The assessment of regional gut transit times in healthy controls and patients with gastroparesis 
using wireless motility technology. Aliment Pharmacol Ther 2010; 31:313-322.

7. Michalek W, Semler JR, Kuo B. Impact of acid suppression on upper gastrointestinal pH and motility. Dig Dis Sci 2011;56:17351742.

8. Zarate N, Mohammed SD, O'Shaughnessy E, et al. Accurate localization of a fall in $\mathrm{pH}$ within the ileocecal region: validation using a dual-scintigraphic technique. Am J Physiol Gastrointest Liver Physiol 2010;299:G1276-G1286.

9. Macfarlene GT, Gibson GR, Cummings JH. Comparison of fermentation reactions in different regions of the human colon. $\mathrm{J}$ Appl Bacteriol 1992;72:57-64.

10. Kuo B, McCallum RW, Koch KL, et al. Comparison of gastric emptying of a nondigestible capsule to a radio-labelled meal in healthy and gastroparetic subjects. Aliment Pharmacol Ther 2008;27:186-196.

11. Maqbool S, Parkman HP, Friedenberg FK. Wireless capsule motility: comparison of the SmartPill GI monitoring system with scintigraphy for measuring whole gut transit. Dig Dis Sci 2009;54:21672174.

12. Camilleri M, Thorne NK, Ringel $\mathrm{Y}$, et al. Wireless $\mathrm{pH}$-motility capsule for colonic transit: prospective comparison with radiopaque markers in chronic constipation. Neurogastroenterol Motil 2010;22: 874-882, e233.

13. Metcalf AM, Philips SF, Zinsmeister AR, MacCarty RL, Beart RW, Wolff BG. Simplified assessment of segmental colonic transit. Gastroenterology 1987;92:40-47.
14. Rauch S, Krueger K, Turan A, You J, Roewer N, Sessler DI. Use of wireless motility capsule to determine gastric emptying and small intestinal transit times in critically ill trauma patients. J Crit Care 2012; 27:534, e7-e12.

15. Gelfond D, Ma C, Semler J, Borowitz D. Intestinal $\mathrm{pH}$ and gastrointestinal transit profiles in cystic fibrosis patients measured by wireless motility capsule. Dig Dis Sci 2013;58:2275-2281.

16. Rao SS, Coss-Adame E, Valestin J, Mysore K. Evaluation of constipation in older adults: radiopaque markers (ROMs) versus wireless motility capsule (WMC). Arch Gerontol Geriatr 2012;55:289294

17. Green AD, Belkind-Gerson J, Surjanhata BC, Mousa H, Kuo B, Di Lorenzo C. Wireless motility capsule test in children with upper gastrointestinal symptoms. J Paediatr 2013;162:1181-1187.

18. Hasler WL, Saad RJ, Rao SS, et al. Heightened colon motor activity measured by a wireless capsule in patients with constipation: relation to colon transit and IBS. Am J Physiol Gastrointest Liver Physiol 2009;297:G1107-G1114.

19. Hasler WL, Rao SS, Parkman HP, et al. Bristol stool form in slow transit constipation correlates inversely with regional colon contractile activity measured by a wireless motility capsule. Gastroenterology 2010;138(suppl 1):S-628.

20. Rozov-Ung I, Mreyoud A, Moore J, et al. Detection of drug effects on gastric emptying and contractility using a wireless motility capsule. BMC Gastroenterology 2014;14:2. 